\title{
MOLECULAR BACKGROUNDS OF INDIVIDUALISED PHARMACOTHERAPY
}

\author{
MONICA NEAMȚU ${ }^{1}$, RĂZVAN NICOLAE RUSU ${ }^{1}$, DANIELA CARMEN ABABEI ${ }^{1 *}$, \\ WALTHER BILD ${ }^{2,3}$, CRISTINA GAVRILOVICI $^{4}$, BOGDAN STANA $^{2}$, VERONICA BILD $^{1,3}$ \\ I "Gr. T. Popa" University of Medicine and Pharmacy, Faculty of Pharmacy, Pharmacodynamics and Clinical Pharmacy \\ Department, Iași, Romania \\ 2 "Gr. T. Popa" University of Medicine and Pharmacy, Faculty of Medicine, Physiology Department, Iași, Romania \\ ${ }^{3}$ Center of Biomedical Research of the Romanian Academy, Iași, Romania \\ 4 “Gr. T. Popa” University of Medicine and Pharmacy, Faculty of Medicine, Paediatrics Department, Iași, Romania
}

*corresponding author: dana.ababei@gmail.com

Manuscript received: September 2019

\begin{abstract}
Genetic polymorphism can influence the effect of drugs by modifying their pharmacokinetics and pharmacodynamics. As a result of these transformations, arise inter-individual differences as a response to drug treatment. While pharmacokinetics follows the amount of drug reaching the therapeutic target, pharmacodynamics follows the manner in which different targets such as receptors, ion channels, and enzymes respond to different drugs. Metabolization of drugs is a natural process that involves the same enzymatic pathways and transport systems used to metabolize different dietary constituents. The cytochrome family (CYP) P450 with three subfamilies, CYP1s, CYP2s and CYP3s, have an essential contribution in the oxidative metabolism for more than $90 \%$ of the drugs used in therapeutics. The specific individual response to medication can also be attributed to genetic factors such as SNPs (single nucleotide polymorphisms), deletions and genetic duplications. These factors together with the physiological conditions (age, sex and ethnicity) can influence the response to medication of the patients. The drug treatment can be personalized for greater effectiveness, but this can be done only on the basis of a very good understanding of the molecular basis of the drug's action and the genetic determinants of the drug response. Pharmacogenetics studies can provide a variety of data regarding the correlation between genetic polymorphisms and response to drug administration.
\end{abstract}

\section{Rezumat}

Polimorfismul genetic poate influența efectul medicamentelor prin modificarea farmacocineticii și farmacodinamicii acestora. În urma acestor transformări iau naștere diferențele interindividuale în ceea ce privește răspunsul la tratamentul medicamentos. În timp ce farmacocinetica urmărește cantitatea de medicament care ajunge la ținta terapeutică, farmacodinamia urmărește maniera în care diferite ținte cum ar fi receptori, canale ionice şi enzime răspund la diferite medicamente. Metabolizarea medicamentele reprezintă un proces natural care implică aceleaşi căi enzimatice și sisteme de transport utilizate și pentru metabolizarea diferiților constituienți din dietă. Din familia (CYP) P450, trei subfamilii, CYP1s, CYP2s și CYP3s, au o contribuție esențială în metabolismul oxidativ pentru mai mult de $90 \%$ dintre medicamentele utilizate în terapeutică. Răspunsul individual specific la medicație poate fi atribuit și factorilor genetici cum ar fi SNP-urile, delețiile și duplicațiile genetice. Acești factori împreună cu condițiile fiziologice (vârstă, sex, etnicitate) pot influența răspunsul pacienților la medicație. Tratamentul medicamentos poate fi personalizat pentru o mai mare eficacitate, dar acest lucru se poate face doar pe baza unei înțelegeri foarte bune a bazelor moleculare a acțiunii medicamentului și a determinanților genetici ai răspunsului medicamentos. Studiile de farmacogenetică pot oferi o multitudine de date în ceea ce privește corelația dintre polimorfismele genetice și răspunsul la administrarea unui medicament.

Keywords: pharmacogenetics, drug metabolism, genetic polymorphism

\section{Introduction}

Pharmacogenomics aims to incorporate the information about the genotype of an individual into therapeutic decisions, targeting the most effective and safe therapy for the individuals. In recent years, significant progress has been made in understanding the genetic differences in pharmacokinetics and pharmacodynamics, in terms of interindividual variability that appears as a response to drugs.
Pharmacogenomics studies how drugs interact with the entire genome, influencing different biological pathways and processes [40]. This branch may not only improve existing therapies but at the same time could lead to the development of new drugs based on a better understanding of the genetic control of cellular functions. The human genome comprises about 20,000 genes responsible for encoding different proteins. It seems that the most common variation is represented by SNP (single nucleotide polymorphism), which is 
defined as the difference of unique base that exists between individuals, with over 22 million of SNPs being identified in the human genome [31].

The goal of pharmacogenomics is to understand how the polymorphism of metabolizing enzymes of certain drugs, transporters and/or receptors can influence the therapy. Lately, a number of advances have been made in deciphering the human genome, leading to an increase in the availability of pharmacogenomic tests. Currently, there are over 100 drugs for which patient testing can bring benefits regarding the improvement of therapy. Until now, pharmacogenomics has proven useful in patients undergoing warfarin therapy, with certain anticancer drugs as well as in pain management with certain opioids. There are important the idiosyncratic dose-independent side effects, the toxicity of some drugs as well as their efficacy. The differences in response to certain drugs in terms of efficacy, therapeutic failure, adverse reactions, and toxicity can be considered as multifactorial polygenic features [41].

There is a great variability in interindividual DNA that governs many characteristics of a person including his ability to respond to a particular drug therapy [9]. SNPs represent over $90 \%$ of the genetic variations in the human genome. The rest of the variations are represented by insertions, deletions, repeats and microsatellites. Depending on the response to a drug, individuals are divided into slow and fast metabolizers. Genetic molecular testing can characterize the gene of an enzyme by demonstrating which alleles are present and how they can affect the enzymatic activity. Some of these alleles may be associated with the loss or impairment of gene functioning. Four types of metabolizers according to the genetic profile of the individuals were differentiated: extensive metabolizers: individuals who have two normal genes and metabolize drugs normally; poor metabolizers: individuals with two non-functional genes which metabolize a drug very slowly compared to a normal individual; ultrafast metabolizers: individuals who have multiple copies of the active genes and can metabolize a certain drug very quickly, so that it has no pharmacodynamic action; intermediate metabolizers: individuals with an active allele and an inactive one for the same gene [7].

\section{Ethnic differences in drug metabolism}

A number of ethnic differences that arise in the response of patients as a result of medication administration have been identified. There are sufficient cases where this interethnic variability evidenced by pharmacogenomic techniques determine that one drug or family of drugs are recommended for one ethnic group and at the same time have low importance for another group. Among the most important ethnic differences, those correlated with the fast acetylator phenotype versus the slow acetylator phenotype are highlighted. The frequency of slow acetylator alleles ranges from less than $10 \%$ in Japanese populations to more than $90 \%$ in some Mediterranean populations [41].

An explanation for the appearance of ethnic differences in drug metabolism was proposed by Gonzalez et al. who assume that the genes studied in pharmacogenomics, in animals, appeared because their diet was based on vegetables. The plant metabolites are similar, taking in consideration their intramolecular composition and molecular weight, with some drugs [18]. Ethnic groups originate from populations that have been geographically isolated for more than 10,000 years and had a distinct diet characteristic for their geographical region and culture. These details could explain the present observations regarding the interethnic differences in drug metabolism and the response to those [39]. The 5 main subgroups of Homo sapiens geographically isolated appear to have been derived from each other 20,000 - 45,000 years ago [63]. It is considered, based on studies performed on different species of animals that a 10,000 years geographic isolation would be sufficient for the appearance of major differences in the genes involved in pharmacogenomics. It is supposed that this situation is due to selective pressure such as differences in diet or exposure to other environmental factors including altitude or climate change. One such example is the significant ethnic differences observed as the response to the consumption of dairy products in lactase deficient populations [26].

This polymorphism could influence the drugs effect by modification of the pharmacokinetics and pharmacodynamics influencing the interindividual response to drugs [45].

The genetic polymorphism of drug transporters and phase I metabolizing enzymes may alter the pharmacokinetic properties of the administered drugs and metabolites or even both at the target site which have as a result the variability of drug response [1].

\section{The polymorphism of enzymes responsible for drug metabolism}

The ability to metabolize drugs is a natural process that involves the same enzymatic pathways and transport systems used to metabolize the different constituents from the diet. These enzymes are named xenobiotic metabolizing enzymes. Lipophilic drugs must be transformed into water-soluble components to facilitate their elimination from the body; otherwise, they are accumulated and became toxic. These enzymes are found in most tissues of the body, the highest levels being reached in the gastrointestinal tract and liver. They are also present in the kidneys, brain and lungs. They are located at the level of intracellular membranes and cytoplasm and are represented by pigments (cytochromes) because they contain the heme group, being present in all prokaryotic and eukaryotic organisms. 
There are several types of cytochromes, but cytochrome P450 plays an important role in drug metabolism. The cytochrome (CYP) P450 family is made up of three subfamilies, namely CYP1s, CYP2s and CYP3s that have an essential contribution to oxidative metabolism for more than $90 \%$ of the drugs used in therapeutics [46]. Among these, CYP2D6 was the most intensively studied $25 \%$ of the drugs currently on the market representing substrates for this isoform although it constitutes only 2 - $4 \%$ of the total hepatic cytochromes [62]. Drugs metabolized by this isoform include antidepressants, antipsychotics, antitussives, analgesics, beta-blocking agents, antiarrhythmic and antiemetic agents [19].

Most drugs are metabolized through phase I reactions that involve oxidation, reduction or hydrolysis reactions whereby the drug is transformed into a water soluble metabolite with a higher polarity. Other drugs pass through the phase II of metabolism through polar group conjugation reactions which will increase the polarity of the drug molecules. The enzymes responsible for such transformations show a wide variation of the enzymatic activities that are due to the genetic polymorphism. The purpose of pharmacogenomics consists in understanding these genetic variations in order to be able to predict the response of a certain patient to a particular drug. The cytochrome P450 oxidase (CYP) family is the most important family involved in drug metabolism and comprises a large group of enzymes that contain the heme group and are found in large quantities in the liver and other organs.

The main CYP isoforms responsible for drug metabolism include CYP1A2, CYP2B6, CYP2C9, CYP2C19, CYP2D6, CYP2E1 and CYP3A4/CYP3A5. The predominant isoform in this family (over $30 \%$ ) is CYP3A4 and is responsible for the metabolism of many drugs. Regarding the genetic polymorphism of CYP2D6, CYP2D9 and CYP2D19, this has been well studied with wide interindividual responses to different drugs. Thus, if the enzymatic activity disappears or is significantly reduced due to this genetic polymorphism then individuals can no longer metabolize a particular drug and its toxic effects may occur [7].

\section{CYP2D6 isoform}

The genetic polymorphism of genes encoding members of the CYP family was first reported for CYP2D6, this highly polymorphic gene being localized on chromosome 22k13.1 and consists of nine exons and eight introns [27]. More than 100 genetic variants of CYP2D6 have been described so far as the result of point mutations, duplication, insertion or deletion of single or multiple nucleotides and even from the deletion of an entire gene. Individuals with allelic variants have been classified as poor, intermediate, extensive and ultra-fast metabolizers in accordance with the metabolic nature of the drug as well as with the degree of involvement in the metabolism of these variants [61].

The marked presence of polymorphism at the mentioned gene significantly affects the phenotypic responses to drugs. There is a 10-fold difference in the dose required to obtain the same plasmatic concentrations in different individuals [28]. The following drugs are used for phenotyping CYP2D6 in vivo: dextromethorphan, debrisoquine, bufuralol and spartein [1]. Pharmacokinetic studies performed so far for CYP2D6 substrates have made possible some dose adjustment recommendations for a series of tricyclic antidepressants in the case of poor, intermediate and ultra-fast metabolizers. Also, for a number of antipsychotic agents, a dose adjustment is recommended, especially for poor and ultra-fast patients [23].

The CYP2D6 isoform is also involved in the metabolism of codeine in its active metabolite with analgesic action, morphine. Ultra-fast metabolizers are a risk group because increased levels of morphine can cause sedation and respiratory depression in both adults and breast-fed children. On the other hand, no benefits were observed in the poor metabolizers due to the reduced metabolization of codeine in morphine [52]. A study using new combinations of maternal genetic markers used to determine codeine toxicity in new-borns and their mothers revealed that CYP2D6 genotype induces an increase in their CNS depression [5]. Based on these effects due to CYP2D6 variants on codeine metabolism, new information has been introduced on drug packaging regarding their increased bioactivation in ultra-fast metabolizers and dose reduction recommendations to avoid overdose symptoms such as drowsiness, confusion and heavy breathing.

\section{CYP2C isoforms}

\section{CYP2C9}

Another important member of the CYP superfamily is the gene encoding CYP2C9 located on chromosome 10q24.2. This isoform represents about $18 \%$ of the total CYP proteins in human liver microsomes [36]. CYP2C9 metabolizes approximately $25 \%$ of the drugs administered including anti-inflammatory agents such as flurbiprofen, hypoglycaemic agents (glipizide and tolbutamide), anticoagulants (S-warfarin) and anticonvulsants (phenytoin) [57]. The interethnic and interindividual variations of CYP2C9 polymorphisms are clinically significant especially in patients undergoing anticoagulant therapy such as warfarin, one of the most commonly prescribed oral anticoagulants [48]. Warfarin used in therapeutics is a racemic mixture of $R$ and $S$ enantiomers, in which the $\mathrm{S}$-isomer has an anticoagulant potency of approximately 5-fold greater than the Risomer. Inactivation of active S-warfarin is almost exclusively mediated by the CYP2C9 isoform [53]. The polymorphisms of genes encoding coagulation factors may contribute to the occurrence of haemorrhagic 
risk, thus it is required an initial warfarin dose adjustment.

\section{CYP2C19}

The CYP2C19 polymorphism was identified on chromosome 10q24 and encodes another member of the CYP family, which can metabolize many commonly, administered therapeutic drugs such as anxiolytics (diazepam), proton pump inhibitors (omeprazole), anticonvulsants (S-mephenytoin) and antimalarial biguanides. Until now, more than 35 variants of CYP2C19 and about 2000 SNPs have been identified, their number increasing constantly [1]. It has been shown that the activity of omeprazole, a drug recommended for the treatment of ulcer and gastrooesophageal reflux disease, is strongly dependent on the CYP2C19 genotype of patients [14]. After administration of omeprazole in a single dose of 20 milligrams, intragastric $\mathrm{pH}$ values of 4.5 were observed for poor metabolizers, 3.3 for heterozygous extensive metabolizers and 2.1 for extensive metabolizers [15]. These data indicate the need to adjust the dose of omeprazole according to the patient's genetic polymorphism in order to obtain the desired therapeutic effects.

\section{CYP3A isoform}

Among the isoforms, CYP3A4 predominates in the white race and CYP3A5 predominates in African Americans [16]. Until now, there are known more than 20 CYP3A4 variants which have altered enzymatic activities ranging from loss of catalytic efficiency between low to significant levels. However, a clear difference between the groups of slow or fast metabolizers could not be highlighted. Many of the variants of the CYP3A4 coding regions occur with reduced frequency and are unlikely to reach 10-fold differences in CYP3A4 activity observed in vivo [32]. The CYP3A5 isoform may contribute to the complexity of these observations which cannot yet be explained because almost all CYP3A4 substrates with a few exceptions are also metabolized by CYP3A5 [16]. CYP3A4 polymorphism is a major concern in the study of disordered interindividual metabolisms of drugs as well as their corresponding adverse reactions, being identified more than 26 variants [6].

The CYP3A5 polymorphism plays an important role in the dosing of tacrolimus in order to obtain the necessary blood concentrations, so individuals expressing this polymorphism require much higher doses to reach the blood concentration corresponding to the therapeutic effect [22]. Randomized, controlled clinical trials that followed the efficacy of tacrolimus dosing based on individual CYP3A5 genotypes compared to a standard dosing regimen based on patients' body weight have shown that pharmacogenetic adaptation of the daily dose of tacrolimus is associated with improvement of obtaining the desired blood concentration
[55]. In vivo studies have shown that the metabolic rates of drugs metabolized by both CYP3A4 and CYP3A5 represent the sum of the activities of both enzymes [1].

\section{Polymorphism of transporter proteins and receptors}

Many responses to drugs are determined by the intervention of certain gene products that influence their pharmacokinetics and pharmacodynamics, such as metabolizing enzymes, drug carriers and receptors. Together with the complete sequencing of the human genome it has been estimated that approximately 500 - 1200 genes encode the transporter proteins for drugs. Compared to drug metabolizing enzymes, much less data are known about the genetic polymorphism of the receptors but still, molecular research has shown that many of these genes exhibit a genetic polymorphism [7].

Membrane transporter proteins are involved in the translocation of different physiological, chemical substances and drugs inside or outside the cells via passive or active transport mechanisms. These carriers can be classified into two broad categories: influx or efflux. Influx transporters include organic anion transporters, organic cationic transporters and oligopeptide transporters. Efflux carriers include the ABC (ATP-binding cassette transporter family) and MATES (multi drug toxin extrusion proteins) [17].

The carriers modulate the absorption, distribution and elimination of drugs performing the inflow or outflow of drugs into the cell, thus affecting the efficacy and toxicity of the drugs [16].

A drug can have both a beneficial and toxic effect on a particular patient depending on the absorption, distribution and excretion rates of the drug. The drug carriers control the movement of all substances and their metabolites, active or inactive inside or outside the cell. Thus, the genes polymorphisms of these transporters can alter the absorption, distribution, excretion rates and last but not least the safety and efficacy of the administered drugs [1]. The most commonly studied membrane transporters include ABC transporters and SLC (solute carriers). These transporter proteins are wide spread in the body depending on their role in the influx or efflux of endogenous compounds and xenobiotics leading to the hypothesis that they play a crucial role in the pharmacokinetics of drugs used in therapeutics [12].

\section{ABC carriers}

ABC carriers are most often involved in the transport of drugs and other substances against the concentration gradient using ATP as an energy source. In this superfamily of $\mathrm{ABC}$ carriers, 49 genes have been identified and are divided into 7 subfamilies from $A B C A$ to ABCG [1]. Research was focused more on ABCB1 
FARMACIA, 2020, Vol. 68, 3

(glycoprotein-P) and ABCG2. The genes in this family encode transmembrane proteins that bind and hydrolyse ATP using energy to transport the various molecules through the membrane. Their genetic variation could most likely modulate the transporter phenotype and thus affect the toxicity and response to drug treatment or disease predisposition [12]. Indeed, the expression of drug transporters can be modulated by endogenous or exogenous factors including drugs, but it is not yet known if whether genetically inherited interindividual differences may also affect the toxicity and efficacy of the drugs. There are multiple factors that can affect the functioning and expression of drug transporters, including genetic mutations, SNPs, transcriptional regulation, messenger RNA stability, post-translational modifications and intracellular localization. The evaluation of these factors is extremely important to understand the whole picture of the pharmacogenomics of drug carriers [25].

$A B C B 1$ gene

This gene is known as the MDR1 (multi drug resistant) gene and encodes a P glycoprotein (Pgp) which is involved in the extracellular transport of numerous chemotherapeutic agents, physiological metabolites, and carcinogenic substances [1].

$\mathrm{ABCB} 1$ is expressed in many healthy organs and appears to play an important role in the elimination of toxic substances or metabolites from the cell. Thus, the protein is strongly expressed in the bloodbrain barrier cells and most likely involved in the transport of toxic compounds from the brain, effectively preventing their entry. It is also expressed in many types of excretory cells such as kidney, liver and intestine where normal physiological functions seem to be involved in the secretion of toxic xenobiotics and metabolites.

The expression of this gene at the apical surface of epithelial cells in the lower gastrointestinal tract (jejunum, ileum, and colon) may influence the intestinal uptake of drugs and limit the oral bioavailability of a wide variety of drugs [50]. Although, ABCB1 protects the brain against xenobiotic exposure and facilitates renal and hepatobiliary excretion; overexpression of this gene in cancer cells induces resistance to chemotherapeutic agents [50].

The effect of ABCB1 polymorphisms on drug efficacy may be due to a high genetic variation of this gene in different populations, as well as to a varied effect of a certain SNP on ABCB1 expression/function in different organs. In the same time could be also determined by a variety of substrates for ABCB1 [16]. ABCG2 gene

ABCG2 was initially discovered in many multidrugresistant cell lines, also known as BCRP (breast cancer resistance protein), MXR (mitoxantrone resistance protein) or $\mathrm{ABCP}$ (placenta-specific $\mathrm{ABC}$ protein) [44]. ABCG2 is expressed in epithelial cells of the small intestine, lungs, kidneys, salivary glands, colon and placenta, playing an essential role for the intestinal absorption and biliary excretion of drugs and their metabolites as well as xenobiotics. More than 80 polymorphisms have been identified for this gene [24]. Also, ABCG2 expression is strongly induced in the mammary gland during lactation, where it appears to be involved in the secretion of certain important nutrients, such as riboflavin (vitamin B2) in milk [56]. Interindividual differences in ABCG2 may contribute to the varied bioavailability and pharmacological response of drugs [17]. The most important clinical effects appear for drugs that have a narrow therapeutic index and reduced bioavailability. Overexpression of ABCG 2 results into an increased efflux of the drug and thus to a subsequent resistance to a variety of anticancer agents including anthracyclines, mitoxantrones and campothecines [42].

The sequencing of ABCG2 transporters allowed the identification of a number of allelic variants that may affect the activity of the products of this gene in vivo. Some of these genetic variants may possibly modulate the ABCG2 phenotype of patients by affecting response to drug treatment and predisposition to toxicity [12]. A number of SNPs have been identified in the gene coding regions for which some of them do not alter protein expression or function, but others may affect the stability of ABCG2-encoded proteins [38].

\section{SLC carriers}

The SLC carriers (solute-carrier) represent 2 superfamilies of transporter proteins that are involved in the uptake, distribution and elimination of drugs [1]. Within the SLC family, approximately 360 genes were identified in 46 subfamilies, divided into 2 major categories, namely OAT (organic anion transporter), OATP (organic anion transporting polypeptides) and OCT (organic cation transporter) [13].

This superfamily of carriers transports organic anions including drugs and metabolites through the cell membrane. OAT transports smaller hydrophilic organic anions while OATP transports larger hydrophobic anions [16].

OAT (organic anion transporters) carriers

Represent one of the most important subfamilies encoded by SLC2A genes. These carriers are responsible for uptake of a wide range of substances including anticancer, antibiotic and antihypertensive drugs. Majority of OATs are located at the level of kidney or liver. In the kidney these carriers use the combined sodium/ potassium-ATP-transport and sodium dicarboxylate cotransporter. An inwardly directed sodium gradient supported by the sodium/potassium ATPase functioning leads to the transport or transfer of dicarboxylate into cells and as a consequence the outwardly transferred dicarboxylate gradient is used by the OAT to introduce its substrates into the cell. This process is energy 
FARMACIA, 2020, Vol. 68, 3

consuming and allows the entry into the cell of anionic substances, regardless of the electrochemical gradients. OAT1. OAT1 has 2 functional variants OAT1-1 and OAT1-2 in the kidney as well as two dysfunctional variants OAT1-3 and OAT1-4. OAT1 can transport a range of substances including antibiotics and anticancer agents [60]. A number of studies have indicated the presence of a genetic polymorphism for OAT1, but so far the functional characterization of these variants is not satisfactory. Since the nonsynonymous polymorphism of OAT1 may not be very frequent, it is important to consider the influence of these polymorphisms in regulating the OAT1 gene expression [58]. It has been indicated the fact that the intergenetic polymorphism of OAT1 and OAT3 may be correlated with the interindividual variation of patients for hydrochlorothiazide [21]. Due to the essential role that OAT1 plays in the renal elimination of drugs and their metabolites as well as different toxins, it is extremely important to evaluate functionally the OAT1 variants in vitro for facilitating the interpretation of in vivo and clinical observations.

$O A T 2$. OAT2 is strongly expressed in the liver and reduced in the kidney, being involved in the transport of different types of organic anions such as: prostaglandin E2 (PGE2), cAMP, methotrexate and glutarate, no regulatory SNPs have been identified for OAT1 and OAT2 [60].

OAT3. OAT3 was also identified in the kidney and at low levels in the adrenal tissue. Although it is localized in the basolateral membrane of the proximal renal tubules together with OAT1, the substrate selectivity of OAT3 is somewhat different from that of OAT1 [3].

OAT4. OAT4 is different from OAT1, OAT2 and OAT3 and is expressed at the apical membrane of the renal proximal tubular cells, as well as, at the basal face of syncytiotrophoblasts. It is involved in the reabsorption of organic anions in the urine as well as in the absorption of steroid precursors from foetal blood. OAT4 substrates include steroid-like sulphate structures, urate from the purine metabolism as well as tetracyclines and methotrexate. OAT4 genetic polymorphism may be associated with altered torsemide renal clearance and diminished renal secretion. However, molecular studies made on OAT4 genotypes cannot yet be used for the interpretation of these results in vivo [60].

OATP (organic anion transporting polypeptides) carriers

OATP represent a large family of membrane transporters responsible for the uptake and assimilation of a variety of endogenous and exogenous substances including bile salts, hormones and drugs such as antibiotics, cardiac glycosides and anticancer agents [37]. Eleven types of OATP transporters were identified, including OATP1A2, AOTP1B1, AOTP1B3,
OATP2B1, AOTPC, which influence the pharmacokinetics of drugs [43]. These drug transporters influence the influx of drugs especially in hepatocytes and renal tubular cells [59].

OATP1B1. OATP1B1 is mainly expressed in the basolateral membrane of human hepatocytes acting as an absorption transporter. Pravastatin, rosuvastatin, atorvastatin, fluvastatin, benzylpenicillin, rifampicin, enalapril, olmesartan and valsartan are among the drug substrates characteristic for this transporter. This transporter is involved in the occurrence of competing drug interactions as well as pharmacokinetic variations due to the genetic polymorphisms in the gene encoding this protein [12]. In therapeutics, the statins (HMGcoA-reductase inhibitors) are well tolerated by patients and appear to have wide safety margins [2]. This class of drugs has a low to average bioavailability and are generally associated with a high interindividual pharmacokinetic variability of up to 10 times or more. A possible cause of this variability is the genetic variation of the genes that encode OATs. Some members of this family can transport statins and include OATP1B1, OATP1B3, OATP2B1 and OATP1A2. Among these carriers, OAT1B1 was best characterized in terms of the association between genetic variants and statin pharmacokinetics [12]. Because the fact that the mechanism of action of statins is dependent on HMG-coA-reductase inhibition in hepatocytes, any decrease in the transport of these drugs into the liver may lead to a decrease in their efficacy and to an increased risk of systemic toxicity, particularly to statins induced myopathy [35]. Certain OATP1B1 variants are associated with increased clearance of methotrexate and its toxicity in children diagnosed with acute lymphoblastic leukaemia [59]. OATP1B3. OATP1B3 is predominantly expressed at the basolateral membrane of hepatocytes and transport a wide range of structurally diverse compounds such as digoxin, docetaxel and paclitaxel [12]. Recently, the role of this transporter has been evaluated for compounds that are considered to be specific markers for cytochrome P450 (CYP) activity [11]. These studies followed the role of SLCs over the non-invasive CYP3A phenotype for midazolam and erythromycin. While midazolam was not identified as a substrate for any of the in vitro tested carriers, erythromycin has been shown to be a good substrate for OATP1B3. Changes were observed regarding the transport of erythromycin which increased significantly in cells expressing a polymorphic variant (334G) of this transporter produced by SNP. However, further studies are needed for a better understanding of the role of pharmacogenetics and how it can improve the efficacy of the drug and reduce its toxicity [12]. OCT (organic cation transporters) carriers)

The OCT family consists of three subtypes of facilitator transporters, namely OCT1 (encoded by the SLC22A1 gene), OCT2 (encoded by the SLC22A2 gene) and 
OCT (encoded by the SLC22A3 gene). These proteins are present in the basolateral cell membrane of the renal proximal tubules [1]. Other locations in the body of the OCT family are represented by the liver and intestine where they play an important role in drug distribution [30]. These carriers mainly mediate the transport of organic cations that are positively charged at physiological $\mathrm{pH}$, inside or outside the cell. They are defined as being polyspecific since they mediate the transport of different substrates with different weights and molecular structures.

OCTs have often been associated with the risk of adverse drug-drug interactions, noting that OCT1 polymorphisms are associated with altered pharmacokinetics of antidiabetic medication (metformin) and tyrosine kinase inhibitor, imatinib [10].

OCT1. OCT1 was first revealed in the liver and was also determined in the luminal membrane of the bronchial epithelial cells and the placenta, where it partially mediates acetylcholine releasing. It can transport the common substrates for OCT but at the same time for some drugs such as metformin. A low activity of the OCT1 allele variants of these polymorphisms decreases the absorption of metformin which results in a decreased response regarding the blood glucose level [51]. A number of studies have shown that OCT1 genetic variations may be associated with metformin effect in patients with type 2 diabetes. Also, it has been shown that OCT1 genotypes have impact on other drugs such as morphine. In children it was shown that OCT1 genotypes strongly influence the kinetics of morphine administered iv, thus, deficient variants of OCT1 may lead to a reduction in morphine clearance, which results in an increased frequency of toxic effects [60].

OCT2. OCT2 has been identified in several tissues in the body but especially in the kidney and in the brain, being expressed in different regions where it mediates the transport of dopamine, serotonin and other neurotransmitters. Due to this fact, a disorder of OCT2 activity is very likely to contribute to neuronal dysfunctions [54]. While OCT1 binds especially to the larger hydrophobic substances, OCT2 binds to the smaller hydrophilic substrates [10]. Besides to the common features of OCTs, it has been shown that OCT2 transports substrates in a bidirectional manner, indicating its role in both the influx and efflux of substances through the cell membrane [60]. Due to its wide distribution in the human body, this transporter is likely to take over the excess of monoamine transmitters that have escaped the neuronal re-uptake, thus avoiding the uncontrolled spread of signals [20].

OCT3. Compared with OCT1 and OCT2, OCT3 has a wide distribution in different tissues having the highest expression in the striated muscles, liver, placenta and heart. Until now, there is little data on OCT3 polymorphism. However, there is an increased susceptibility to hypertension, allergic and neuropsychiatric diseases in individuals with OCT3 dysfunction regarding the clearance of endogenous organic cations such as histamines and monaminergic transmitters [60]. Currently was demonstrated the fact that OCT3 is capable of transporting cationic substances such as histamine. Due to its expression in several territories, at the level of peripheral tissues, it has been shown to play an important role in the distribution and elimination of metformin in these tissues [4].

\section{Gene polymorphism of therapeutic targets}

Pharmacodynamics tracks both the biochemical and physiological effects of drugs in the body, as well as the relationship between drug concentration and the effect produced by them. Drugs exert their effects through interactions with different types of proteins, including cell surface receptors (beta-adrenergic, serotoninergic and $\mu$-opioid receptors), enzymes (epoxide-reductase complex 1, vitamin $\mathrm{K}$, adenosine monophosphate-activated protein kinase and catecholO-methyltransferase) as well as proteins that form ionic channels (sodium and potassium channels and sodium epithelial channels). Also, many intracellular signalling proteins are involved in the onset of the drug response. Genetic variations that affect both the activity and expression of an intracellular signalling protein or drug target may have important consequences for the pharmacodynamic response to a drug. The phenotypic response to the genetic variation of the target proteins of the drugs, generally differs from that of the metabolizing enzymes and of the drug transporters [31].

Therapeutic targets can be classified into 3 main categories, namely: proteins; signal transduction cascade and proteins involved in different pathologies.

The genetic variations of these targets affect the response to drugs and implicitly the interindividual variability, thus being the response of the patients to the administered therapy.

The ACE genes encode the angiotensin I conversion enzyme that catalyses the conversion of angiotensin I decapepide into a potent vasoconstrictor octapeptide, angiotensin II, and degradation of bradykinin which is a potent vasodilator. ACE represent the main target in the treatment of hypertension, congestive heart failure and diabetic nephropathy. Insertion polymorphisms of the ACE gene are correlated with increased serum levels of the conversion enzyme while deletion polymorphisms are associated with low levels of ACE, which indicate that the insertion/deletion polymorphisms play an important role in the total phenotypic variation of this enzyme at the serum level [49].

Angiotensin converting enzyme (ACE) inhibitors and beta-blockers are drugs that play an important role in the treatment of hypertension and heart failure. The 
$\beta 2$ receptor is a target for $\beta$ agonists and is encoded by the ADRB2 gene, the genetic variants of this gene being responsible for altering the signal transduction processes by these receptors $[8,33]$.

SNPs of the ADRB2 gene were correlated with altered expression and down regulation in response to $\beta 2$ receptor agonists [33]. Changes in SNP amino acids can have a significant functional impact on drug treatment [34].

The interindividual variability of the response to drugs is a major concern in the management of different diseases but also in the development of new drugs. Different drug responses can often be due to the genetic polymorphism of genes involved in the pharmacokinetics of drugs as well as their pharmacodynamics. The variability of response to a drug can lead to therapeutic failure or even of the adverse effects in some individuals. Unfortunately, the prospective identification of those patients who should benefit from a particular therapy is not currently possible as a routine investigation for many diseases and medications.

The drug treatment can be personalized in order to achieve a greater efficacy only if there is a better understanding of the molecular basis of the action of drugs as well as the genetic determinants of the drug response. The role of pharmacogenomics is essential in determining the role of inheritances of differences that occur in response to a drug, thus being able to identify the genetic variants that influence the response to certain treatments in order to adjust the treatment based on the patient's genetic profile [16]. Pharmacogenetic testing has become prevalent with the discovery of gene-monogenic drug interactions, making possible the pharmacogenetic testing based on which a clinician can find out the effectiveness of a treatment or the occurrence of an adverse reaction. Together with the advances in molecular technology including genotyping and sequencing of the genetic material of patients, ideally from an early age (even at birth), it appears the possibility to store these results and use them when needed throughout the life of the patient [29]. Of course, these results will only include inherited DNA mutations, and for somatic mutations (those that are not inherited) will be necessary a testing during the patient life depending on the status of the disease (e.g. cancer) [47].

\section{Conclusions}

Pharmacogenomics involves the understanding of the individual response to drug therapy taking in consideration that each individual has a different genetic background that may influence the risk of developing certain diseases, as well as responses to the action of drugs or environmental factors.

A lot of progress was made in understanding the interindividual variations in response to a drug. Due to the fact that each patient may respond differently to a particular drug, the therapeutic efficacy or inefficiency of the treatment may be explained. The therapeutic inefficiency may lead to the appearance of severe adverse effects or even to the death of the patient, thus explaining the individual variability in the effectiveness and safety of the therapy.

This variation of the interindividual response is determined primarily by the pharmacokinetic and pharmacodynamic properties of the drugs, being influenced both directly and indirectly by the polymorphism of certain genes of the metabolizing enzymes or membrane transporters.

Genes encoding proteins involved in determining the bioavailability of drugs such as transporter proteins and enzymes involved in metabolism are important to be studied in order to determine the variability of the response in therapy.

The specific individual response to medication may also be attributed to genetic factors such as SNPs or genetic deletions and duplications. These factors together with the physiological conditions (age, sex and ethnicity) can influence the response to medication. Along with these factors, environmental factors are very important, such as toxins or diet as well as the pathological factors, renal or hepatic function, diabetes and obesity. Responses to drugs administration can be varied and often are permanent if they are generated by genetic factors, whereas those that are influenced by other factors are usually transient.

The drug treatment can thus be personalized for greater efficacy, but this can be done only on the basis of a very good understanding of the molecular basis of the drug's action and of the genetic determinants of the drug response. Pharmacogenetics studies can provide a wealth of data regarding the correlation between genetic polymorphisms and response to drug administration. Although it is a new field, the concept of personalized medicine is beginning to accumulate more and more evidence and data extremely useful in individualization of the treatment.

Pharmacogenomics can influence drug dosage, efficacy and toxicity, being important in the clinical practice. However, the identification of genetic markers associated with drug responses is not always correlated with useful clinical predictors and in most cases requires independent replication of the genotypephenotype association prior to clinical implementation.

\section{Conflict of interest}

The authors declare no conflict of interest.

\section{References}

1. Ahmed S, Zhou Z, Zhou J, Chen SQ, Pharmacogenomics of drug metabolizing enzymes and transporters: relevance to precision medicine. Genomics, Proteomics \& Bioinformatics, 2016; 14(5): 298-313. 
2. Bays H, Statin safety: an overview and assessment of the data - 2005. Am J Cardiol., 2006; 97(8A): 6C-26C.

3. Cha SH, Sekine T, Fukushima JI, Kanai Y, Kobayashi Y, Goya T, Endou H. Identification and characterization of human organic anion transporter 3 expressing predominantly in the kidney. Mol Pharmacol., 2001; 59(5): 1277-1286.

4. Chen EC, Liang X, Yee SW, Geier EG, Stocker SL, Chen L, Targeted disruption of organic cation transporter 3 attenuates the pharmacologic response to metformin. Mol Pharmacol., 2015; 88(1): 75-83.

5. Cornelis MC, Byrne EM, Esko T, Nalls MA, Ganna A, Paynter N, Genome-wide meta-analysis identifies six novel loci associated with habitual coffee consumption. Mol Psychiatry, 2014; 20(5): 647-656.

6. Danielson PB, The cytochrome P450 superfamily: biochemistry, evolution and drug metabolism in humans. Curr Drug Metab., 2002; 3(6): 561-597.

7. Dasgupta A, Wahed A, Clinical Chemistry, Immunology and Laboratory Quality Control 1st Edition-A Comprehensive Review for Board Preparation, Certification and Clinical Practice (Chapter 20), Elsevier, USA, San Diego and Waltham, 2014; 353-356.

8. Dishy V, Sofowora GG, Xie HG, Kim RB, Byrne DW, Stein CM, The Effect of Common Polymorphisms of the 32 -Adrenergic Receptor on Agonist-Mediated Vascular Desensitization, N Engl J Med., 2001; 345: 1030-1035.

9. Drăgoi CM, Moroşan E, Dumitrescu IB, Nicolae AC, Arsene AL, Drăgănescu D, Lupuliasa D, Ioniţă AC, Pantea Stoian A, Nicolae C, Rizzo M, Mititelu M, Insights into chrononutrition: the innermost interplay amongst nutrition, metabolism and the circadian clock, in the context of epigenetic reprogramming. Farmacia, 2019; 67(4): 557-571.

10. Fahrmayr C, Fromm MF, König J, Hepatic OATP and OCT uptake transporters: their role for drugdrug interactions and pharmacogenetic aspects. Drug Metab Rev., 2010; 42(3): 380-401.

11. Franke RM, Baker SD, Mathijssen RH, Schuetz EG, Sparreboom A, Influence of solute carriers on the pharmacokinetics of CYP3A4 probes. Clin Pharmacol Ther., 2008; 84(6): 704-709.

12. Franke RM, Gardner ER, Sparreboom A, Pharmacogenetics of drug transporters. Curr Pharm Des., 2010; 16(2): 220-230.

13. Fujita T, Brown C, Carlson EJ, Taylor T, de la Cruz M, Johns SJ, Functional analysis of polymorphisms in the organic anion transporter, SLC22A6 [OAT1]. Pharmacogenetics Genomics, 2005; 15(4): 201-209.

14. Furuta T, Ohashi K, Kosuge K, Zhao XJ, Takashima M, Kimura M, CYP2C19 genotype status and effect of omeprazole on intragastric $\mathrm{pH}$ in humans. Clin Pharmacol Ther., 1999; 65(5): 552-561.

15. Furuta $\mathrm{T}$, Shirai $\mathrm{N}$, Sugimoto M, Ohashi K, Ishizaki $\mathrm{T}$, Pharmacogenomics of proton pump inhibitors. Pharmacogenomics, 2004; 5(2): 181-202.

16. Ghodke-Puranik YA, Lamba JK, Innovative Approaches in Drug Discovery, Ethnopharmacology, Systems Biology and Holistic Targeting (Chapter 7), Elsevier, USA, San Diego and Cambridge, 2017; 195-234
17. Giacomini KM, Huang SM, Tweedie DJ, Benet LZ, Brouwer KL, Chu X, Membrane transporters in drug development. Nat Rev Drug Discov., 2010; 9(30): 215-236.

18. Gonzales FJ, Nebert DW, Evolution of the P450 gene superfamily: animal-plant "warfare", molecular drive, and human genetic differences in drug oxidation. Trends Genet., 1990; 6(6):182-186.

19. Gopisankar MG, CYP2D6 pharmacogenomics. Egyptian J Med Human Genet., 2017; 18(4): 309-313.

20. Gründemann D, Schechinger B, Rappold GA, Schömig E, Molecular identification of the corticosteronesensitive extraneuronal catecholamine transporter. Nat Neurosci., 1998; 1(5): 349-351.

21. Han YF, Fan XH, Wang XJ, Sun K, Xue H, Li WJ, Wang YB, Chen JZ, Zhen YS, Zhang WL, Zhou X, Association of intergenic polymorphism of organic anion transporter 1 and 3 genes with hypertension and blood pressure response to hydrochlorothiazide. Am J Hypertens., 2011; 24(3): 340-346.

22. Hesselink DA, van Schaik RH, van der Heiden IP, van der Werf M, Gregoor PJ, Lindemans J, Genetic polymorphisms of the CYP3A4, CYP3A5, and MDR1 genes and pharmacokinetics of the calcineurin inhibitors cyclosporine and tacrolimus. Clin Pharmacol Ther., 2003; 74(3): 245-254.

23. https://www.pharmacytimes.com/publications/speci alty-pharmacy-times/2013/May_June-2013/TheApplication-of-Drug-Dosing-Guidelines-Based-onPreemptive-Genetic-Testing

24. Iida A, Saito S, Sekine A, Mishima C, Kitamura Y, Catalog of 605 single-nucleotide polymorphisms [SNPs] among 13 genes encoding human ATP-binding cassette transporters: $\mathrm{ABCA} 4, \mathrm{ABCA7}, \mathrm{ABCA} 8, \mathrm{ABCD} 1$, ABCD3, ABCD4, ABCE1, ABCF1, ABCG1, ABCG2, ABCG4, ABCG5, and ABCG8. J Hum Genet., 2002; 47(6): 285-310.

25. Ishikawa T, Onishi Y, Hirano H, Oosumi K, Nagakura M, Tarui S, Pharmacogenomics of drug transporters: a new approach to functional analysis of the genetic polymorphisms of ABCB1 [P-glycoprotein/MDR1]. Biol Pharm Bull., 2004; 27(7): 939-948.

26. Järvelä I, Torniainen S, Kolho KL, Molecular genetics of human lactase deficiencies. Ann Med., 2009; 41(8): 568-575.

27. Kimura S, Umeno M, Skoda RC, Mezer UA, Gonzalez $\mathrm{JF}$, The human debrisoquine 4-hydroxylase (CYP2D) locus: sequence and identification of the polymorphic CYP2D6 gene, a related gene, and a pseudogene. Am J Human Genet., 1989; 45(6): 889-904.

28. Kotowski M, Bogacz A, Bartkowiak-Wieczorek J, Sienko J, Tejchman K, Dziewanowski K, Ostrowski M, Czerny B, Grześkowiak E, Machaliński B, Effect of Interleukin-6 polymorphism on function of the renal allograft funtion and efficacy of immunosuppressive therapy. Farmacia, 2018; 66(5): 791-797.

29. Kisor DF, Sprague JE, The Application of DrugDosing Guidelines Based on Preemptive Genetic Testing. Specialty Pharmacy Times, 2013; 16: 44: 31.

30. Koepsell H, Endou H, The SLC22 drug transporters family. Pflugers Arch., 2004; 447(5): 666-676.

31. Lam YWF, Pharmacogenomics $2^{\text {nd }}$ Edition-Challenges and Opportunities in Therapeutic Implementation 
(Chapter 1), Academic Press, USA, San Diego and Cambridge, 2018; 37.

32. Lamba JK, Lin YS, Thummel K, Daly A, Watkins $\mathrm{PB}$, Strom S, Common allelic variants of cytochrome P4503A4 and their prevalence in different populations. Pharmacogenetics, 2002; 12(2): 121-132.

33. Liggett SB, Beta(2)-adrenergic receptor pharmacogenetics. Am J Respir Crit Care Med., 2000; 161(2): 197-201.

34. Lima JJ, Thomason DB, Mohamed MHN, Eberle $\mathrm{LV}$, Self TH, Impact of genetic polymorphisms of the $\beta 2$-adrenergic receptor on albuterol bronchodilator pharmacodynamics. Clinic Pharmacol Therapeut., 1999; 65(5): 519-525.

35. Link E, Parish S, Armitage J, Bowman L, Heath S, Matsuda F, SLCO1B1 variants and statin-induced myopathy--a genomewide study. $N$ Engl J Med., 2008; 359(8): 789-99.

36. Miners JO, Birkett DJ, Cytochrome P4502C9: an enzyme of major importance in human drug metabolism. Br J Clin Pharmacol., 1998; 45(6): 525-538.

37. Mwinyi J, Johne A, Bauer S, Roots I, Gerloff T, Evidence for inverse effects of OATP-C (SLC21A6) 5 and $1 \mathrm{~b}$ haplotypes on pravastatin kinetics. Clin Pharmacol Ther., 2004; 75(5): 415-421.

38. Nakagawa H, Tamura A, Wakabayashi K, Hoshijima K, Komada M, Yoshida T, Ubiquitin-mediated proteasomal degradation of non-synonymous SNP variants of human $\mathrm{ABC}$ transporter $\mathrm{ABCG}$. Biochem J., 2008; 411(3): 623-631.

39. Nebert DW, Dieter MZ, The Evolution of Drug Metabolism. Pharmacology, 2000; 61(3): 124-135.

40. Nebert DW, Pharmacogenetics and pharmacogenomics: who is this relevant to the clinical genetics?. Clin Genet., 1999; 56(4): 247-258.

41. Nebert DW, Zhang G, Emery and Rimoin's Principles and Practice of Medical Genetics and Genomics ( $7^{\text {th }}$ Edition) (Chapter 16), Academic Press, USA, 2019; 461.

42. Ni Z, Bikadi Z, Rosenberg MF, Mao Q, Structure and function of the human breast cancer resistance protein [BCRP/ABCG2]. Curr Drug Metab., 2010; 11(7): 603-617.

43. Niemi M, Role of OATP transporters in the disposition of drugs. Pharmacogenomics, 2007; 8(7): 787-802.

44. Pedersen JM, ATP-Binding-Cassette Transporters in Biliary Efflux and Drug-Induced Liver Injury. PhD thesis, Uppsala University; 2013.

45. Pirmohamed M, Personalized Pharmacogenomics: Predicting Efficacy and Adverse Drug Reactions. Ann Rev Genom Human Genet., 2014; 15: 349-370.

46. Preissner SC, Hoffmann MF, Preissner R, Dunkel $\mathrm{M}$, Polymorphic cytochrome P450 enzymes (CYPs) and their role in personalized therapy. PloS One, 2013; 8(12): 1-12.

47. Relling MV, Evans WE, Pharmacogenomics in the clinic. Nature, 2015; 526(7573): 343-350.

48. Rettie AE, Tai G, The pharmocogenomics of warfarin: closing in on personalized medicine. Mol Interv., 2006; 6(4): 223-227.

49. Rigat B, Hubert C, Alhenc-Gelas F, Cambien F, Corvol $\mathrm{P}$, Soubrier F, An insertion/deletion polymorphism in the angiotensin I-converting enzyme gene accounting for half the variance of serum enzyme levels. J Clin Investig., 1990; 86(4): 1343-1346.

50. Schellens JH, Malingré MM, Kruijtzer CM, Bardelmeijer $\mathrm{HA}$, van Tellingen $\mathrm{O}$, Schinkel AH, Beijnen JH, Modulation of oral bioavailability of anticancer drugs: from mouse to man. Eur J Pharm Sci., 2000; 12(2): 103-110.

51. Shu Y, Sheardown SA, Brown C, Owen RP, Zhang $S$, Castro RA, Effect of genetic variation in the organic cation transporter 1 (OCT1) on metformin action. J Clin Invest., 2007; 117(5): 1422-1431.

52. Sulem P, Gudbjartsson DF, Geller F, Prokopenko I, Feenstra B, Aben KK, Sequence variants at CYP1A1CYP1A2 and AHR associate with coffee consumption. Hum Mol Genet., 2011; 20(10): 2071-2077.

53. Takahashi $\mathrm{H}$, Echizen $\mathrm{H}$, Pharmacogenetics of warfarin elimination and its clinical implications. Clin Pharmacokinet., 2001; 40(8): 587-603.

54. Takeda M, Khamdang S, Narikawa S, Kimura H, Hosoyamada M, Cha SH, Sekine T, Endou H, Characterization of methotrexate transport and its drug interactions with human organic anion transporters. J Pharmacol Exp Ther., 2002; 302(2): 666-671.

55. Thervet E, Loriot MA, Barbier S, Buchler M, Ficheux M, Choukroun G, Optimization of initial tacrolimus dose using pharmacogenetic testing. Clin Pharmacol Ther., 2010; 87(6): 721-726.

56. van Herwaarden AE, Wagenaar E, Merino G, Johan JW, Rosing H, Beijnen JH, Multidrug Transporter ABCG2/Breast Cancer Resistance Protein Secretes Riboflavin [Vitamin B2] into Milk. Mol Cell Biol., 2007; 27(4): 1247-1253.

57. Wang D, Sun X, Gong Y, Gawronski BE, Langaee TY, Shahin MH, CYP2C9 Promoter Variable Number Tandem Repeat Polymorphism Regulates mRNA Expression in Human Livers. Drug Metab Dispos., 2012; 40(5): 884-891.

58. Xu G, Bhatnagar V, Wen G, Hamilton BA, Eraly SA, Nigam SK, Analyses of coding region polymorphisms in apical and basolateral human organic anion transporter (OAT) genes (OAT1 (NKT), OAT2, OAT3, OAT4, URAT (RST)). Kidney Int., 2005; 68(4): 1491-1499.

59. Yiannakopoulou E, Pharmacogenomics of phase II metabolizing enzymes and drug transporters: clinical implications. Pharmacogenomics J., 2013; 13(2): 105-109.

60. Zhou F, Zhu L, Wang K, Murray M, Recent advance in the pharmacogenomics of human Solute Carrier Transporters (SLCs) in drug disposition. Adv Drug Deliv Rev., 2017; 116: 21-36.

61. Zhou SF, Di YM, Chan E, Du YM, Chow VD, Xue CC, Lai X, Wang JC, Li CG, Tian M, Duan W, Clinical pharmacogenetics and potential application in personalized medicine. Curr Drug Metab., 2008; 9(8): 738-784.

62. Zhou SF, Polymorphism of Human Cytochrome P450 2D6 and Its Clinical Significance. Clinic Pharmacokin., 2009; 48: 689-723.

63. Zvhivotovsky LA, Rosenberg NA, Feldman MW, Features of Evolution and Expansion of Modern Humans, Inferred from Genome wide Microsatellite Markers. Am J Hum Genet., 2003, 72(5): 1171-1186. 